DOI: https://doi.org/10.21721/p2p.2018v5n1.p26-42

\title{
PRODUÇÃO CIENTÍFICA BRASILEIRA E PATENTES DEPOSITADAS NO BRASIL EM CÉLULAS-TRONCO
}

\author{
Fernanda Bochi ${ }^{1}$ \\ Universidade Federal do Rio Grande do Sul (UFRGS)
}

\author{
Rene Faustino Gabriel Junior ${ }^{2}$ \\ Universidade Federal do Rio Grande do Sul (UFRGS) \\ rene.gabriel@ufrgs.br
}

Thiago Monteiro Alves ${ }^{3}$

Universidade Federal do Rio Grande do Sul (UFRGS)

Ana Maria Mielniczuk de Moura ${ }^{4}$

Universidade Federal do Rio Grande do Sul (UFRGS)

\begin{abstract}
Resumo
Os estudos em células tronco têm crescido nos últimos anos. Visando observar a relação entre a produção científica e tecnológica na temática, este trabalho investiga na perspectiva da ciência com a análise de artigos brasileiros publicados sobre células-tronco indexados na Scopus entre os anos de 2013 e 2017. E na perspectiva da tecnologia, analisa a produção tecnológica na forma de patentes depositadas no Brasil sobre o mesmo tema, indexadas na Derwent Innovation Index, sem delimitação temporal. $\mathrm{O}$ artigo constitui um estudo bibliométrico de caráter descritivo, e apresenta as principais instituições, pesquisadores e temáticas relacionadas a pesquisa, desenvolvimento e inovação (PD\&I) na área, identifica os países que colaboram com o Brasil na ciência e os principais escritórios que depositaram patentes no país, os autores e inventores que mais publicam sobre célulastronco e os principais depositantes e áreas do conhecimento nas duas esferas (ciência e tecnologia). A produção científica nacional sobre células-tronco publicadas entre os períodos de 2013 a 2017 sofreu grande ascensão, chegando a 10.569 documentos. Desses documentos, 72,2\% são artigos, $18 \%$ é artigo de revisão, 4,8\% são capítulos de livros, $1.2 \%$ são livros, $1,0 \%$ são trabalhos em eventos e $2,8 \%$ são os demais tipos de documentos. Quanto a produção tecnológica, observou-se que o número de patentes em células-tronco totalizou em 1.375 documentos. O estudo mostra que o Brasil vem se destacando na produção científica, principalmente na área de medicina, bioquímica e genética molecular, enquanto os depósitos de patentes não demostram o mesmo crescimento, concentrando principalmente nos grandes laboratórios de fármacos.
\end{abstract}

Palavras-chave: Produção Científica. Produção Tecnológica. Células-tronco. Bibliometria. Patentometria.

\section{BRAZILIAN SCIENTIFIC PRODUCTION AND PATENTS DEPOSITED IN BRAZIL IN STEM CELLS}

\author{
Abstract \\ Stem cell studies have been growing in recent years. Aiming at observing the relationship between scientific and \\ technological production in this field, this paper investigates from the perspective of science the analysis of \\ Brazilian articles published on stem cells indexed in Scopus between the years of 2013 and 2017. And from a \\ ${ }^{1}$ Mestranda do Programa de Pós-Graduação em Comunicação da Universidade Federal do Rio Grande do Sul \\ (UFRGS) \\ ${ }^{2}$ Professor Doutor do Programa de Pós-Graduação em Ciência da Informação (PPGCIN) da UFRGS; \\ rene.gabriel@ufrgs.br \\ ${ }^{3}$ Discente e bolsista de Iniciação Científica da UFRGS. \\ ${ }^{4}$ Professora Doutra do Programa de Pós-Graduação em Ciência da Informação (PPGCIN) da UFRGS.
}

P2P \& INOVAÇÃO, Rio de Janeiro, v. 5 n. 1, p.26-42, Set./Fev. 2018. 
technology perspective, it analyzes the technological production in the form of patents deposited in Brazil on the same subject, indexed in the Derwent Innovation Index, without temporal delimitation. The article is a descriptive bibliometric study, and presents the main institutions, researchers and topics related to research, development and innovation (PD \& I) in the area, identifies the countries that collaborate with Brazil in science and the main offices that have filed patents in the country, authors and inventors who publish more on stem cells and the main depositors and areas of knowledge in both spheres (science and technology). The national scientific production on stem cells published between the periods of 2013 to 2017 has undergone a great increase, reaching 10,569 documents. Of these documents, $72.2 \%$ are articles, $18 \%$ is a review article, $4.8 \%$ are book chapters, $1.2 \%$ are books, $1.0 \%$ are work on events and $2.8 \%$ are other types of documents. As for technological production, it was observed that the number of patents on stem cells totaled 1,375 documents. The study shows that Brazil has been standing out in the scientific production, mainly in the area of medicine, biochemistry and molecular genetics, while patent deposits do not show the same growth, concentrating mainly in the large drug labs.

Keywords: Scientific production. Technological Production. Stem cells. Bibliometria. Patentometry.

\section{INTRODUÇÃO}

Estudos sobre células-tronco têm despertado o interesse de pesquisadores nas diferentes áreas do conhecimento e na sociedade como um todo. Os fatores que suscitam tais interesses são a capacidade que as células-tronco têm de se dividir e originar novas células com características mais especializadas. Elas têm um potencial de auto-renovação muito intenso, proporcionando tratamento para as mais variadas doenças. Porém, devido às diversas polêmicas quanto ao uso e manuseio de organismos genéticos, discussões filosóficas, sociais, econômicas, jurídicas, sobre ética e moral avançam mundialmente.

No Brasil normas de segurança e mecanismos de fiscalização no uso das técnicas de engenharia genética são pensadas desde 1995, com a Lei 8.974/95 (BRASIL, 1995). Tal lei regulamentava os incisos II e V do art. 225 da Constituição Federal (1988) atribuindo ao poder público o dever de preservar a diversidade e a integridade do patrimônio genético do país, bem como fiscalizar as instituições de pesquisa de organismos geneticamente modificados (OGM). Dez anos depois, essa lei foi substituída pela Lei de Biossegurança 11.105/05 (BRASIL, 2005), que atualizou os termos da regulação de OGM no Brasil, incluindo pesquisa em contenção, experimentação em campo, transporte, importação, produção, armazenamento e comercialização, regulando o uso da biotecnologia no país. Sendo reconhecida internacionalmente, tornou-se uma das mais rígidas e completas leis do mundo.

Para o Brasil, atuar efetivamente em pesquisa de interesse mundial, atrai olhares e investimentos necessários para o desenvolvimento da Ciência e Tecnologia. Sendo pioneiro em transplante de medula óssea, ganhou destaque em 2001 ao criar o Primeiro Banco Privado de Células de Sangue de Cordão Umbilical e Placentário do Brasil, marcando a pesquisa com células-tronco no país, desenvolvendo pesquisas clínicas no tratamento de doenças 
degenerativas, sistema cardiovascular e sistema nervoso, colocando o Brasil entre os países que mais investem em pesquisas com células-tronco.

Conceitualmente, células, assim como uma engrenagem, estabelecem interação entre seus componentes, proporcionando um melhor funcionamento da máquina chamada vida. Elas, com seu poder de automanutenção, realizam todas as funções fundamentais dos seres vivos, como por exemplo, reprodução, crescimento, alimentação, movimentação e até mesmo reação a estímulos externos. Contendo informações genéticas e hereditárias, são elas que controlam e mantem as atividades dos organismos.

De acordo com Nardi (2007), as mais de 200 células que compõe o nosso organismo têm a capacidade de dividir-se por meio do processo conhecido como mitose, além de mudarem de tamanho, forma e morrerem. Esse processo de morte celular, também conhecido como renovação celular, é fundamental para manter o organismo em pleno funcionamento. Segundo a autora (NARDI, 2007), a renovação celular de alguns organismos só ocorre por meio das células-tronco existentes em seus tecidos, uma vez que estas são capazes de se proliferar originando células jovens exatamente iguais a ela ou diferentes tipos de células maduras.

Historicamente, os primeiros estudos com células-tronco, segundo Rodrigues (2006) e Machado (2015), foram realizados em camundongos por volta da década de 1950 e 1960. De acordo com esses autores, o pesquisador Leroy Stevens, enquanto estudava transplantes de tumor em camundongos, observou que no saco escrotal de um deles havia diversos tecidos, como ósseo, sanguíneo, entre outros. Thompson et al. (1998) alegam, por sua vez, que célulastronco embrionárias dos camundongos contribuem para uma ampla gama de tecidos adultos, incluindo células germinativas. Segundo os autores, somente em 1998 foi possível isolar as primeiras células-tronco embrionárias (pluripotentes), proporcionando aos pesquisadores compreenderem a capacidade que essas células têm de desenvolver todos os tecidos humanos.

Devido ao alto poder terapêutico que as células-tronco apresentam em doenças degenerativas e terminais, muitos países são atraídos por pesquisas como essas. Diante disso, o Brasil mostrou grande interesse nessa temática, tornando-se, segundo Aragão e Bezerra (2012), o primeiro país da América-Latina a realizar um transplante de medula óssea, içando recursos e investidores à pesquisa.

Conforme afirmam Aragão e Bezerra (2012), Ministérios como o da Saúde (MS), da Ciência e Tecnologia (MCT), o Conselho Nacional de Desenvolvimento Científico e Tecnológico (CNPq) e a Financiadora de Estudos e Projetos (FINEP) estão mobilizados e investindo em pesquisa com terapia celular. Devido aos avanços nas pesquisas e aos investimentos que foram realizados, em 2005 foi aprovado no Congresso Nacional a Lei de 
Biossegurança 11.105/05, que autorizou, para fins de pesquisa, o uso de células-tronco embrionárias armazenadas a mais de três anos em clínicas de fertilização in vitro. (DINIZ; AVELINO, 2009). Com os avanços tecnológicos, o Brasil foi o primeiro país da América Latina a desenvolver células-tronco pluripotentes induzidas - iPSC, tornando-se o quinto país do mundo a dominar a técnica de reprogramação (células-tronco iPSC, desenvolvidas em laboratório, originadas da primeira fase embrionária), ficando atrás apenas dos Estados Unidos, Japão, Alemanha e China (ARAGÃO; BEZERRA, 2012).

Devido aos diferentes tipos de células-tronco e a maneira como essas são manipuladas, percebe-se que existem variações entre estudos. Pensando em minorar qualquer dificuldade de compreensão quanto os tipos de células-tronco, foram adotadas as principais classificações, tal como o estudo de Santin, Nunez e Moura (2015). Barfoot (2013, tradução nossa) classifica as células-tronco em: a) células-tronco teciduais (tissue stem cell) - só geram células de órgãos ou tecidos a que pertence, ou seja, células-tronco hematopoiéticas geram sangue, células-tronco da pele gera pele, e assim por diante; b) células-tronco embrionárias (embryonic stem cells) - são células-tronco pluripotentes (pluripotent stem cells) derivados de embriões precoces, ou seja, da primeira fase do desenvolvimento do feto; c) células-tronco pluripotentes induzidas (induced pluripotent stem cells) - células-tronco adultas geneticamente reprogramadas, gerando diferentes tipos de células; d) células-tronco epiblásticas (epiblast stem cells) - são células pluripotentes isoladas em camundongos, derivadas de um estágio ligeiramente posterior desenvolvimento embrionário. Essas classificações foram utilizadas como expressões de busca na base de dados Scopus, detalhadas na metodologia.

A produção de tecnologias está ligada de forma direta ou indiretamente a Ciência, sendo também retroalimentada por ela. Desta forma as inovações tecnológicas devem ser observadas em conjunto com a pesquisa científica. Para Brisolla et al. (1997), que estudaram a área de biotecnologia, destacam que os conhecimentos científicos aliados à técnica necessária para intervenção e modificação na natureza demonstram que a área se situa entre essas duas esferas, ciência e tecnologia, possibilitando que o estudo da interação entre a produção científica e tecnológica atinja os objetivos propostos.

Sendo assim, considerando a importância da pesquisa sobre tal temática, esse artigo visa analisar a produção científica brasileira e as patentes depositadas no Brasil sobre células-tronco, indexadas na base de dados Scopus no período entre 2013 a 2017 assim como as patentes depositadas no Brasil e indexadas na Derwent Innovation Index (DII), de forma a investigar a correspondência entre a produção científica e a tecnológica nesta área no Brasil. Para tanto, o artigo constitui um estudo bibliométrico e patentométrico de caráter descritivo, onde investiga- 
se as principais instituições que investem na Pesquisa, Desenvolvimento e Inovação (PD\&I). Analisou-se os países que colaboram com o Brasil na ciência, as áreas de pesquisa das publicações científicas assim como os maiores depositantes e áreas do conhecimento reveladas nas patentes depositadas no Brasil.

\section{METODOLOGIA}

Trata-se de um estudo descritivo, com abordagem bibliométrica e patentométrica, visando analisar os documentos brasileiros indexados na Scopus e as patentes depositadas no Brasil, e indexadas na DII sobre a temática célula-tronco. A coleta de dados foi realizada durante o mês de fevereiro de 2018 e buscou todos os estudos sobre células-tronco no Brasil, no período de 2013 a 2017 na SCOPUS e na DII, não foi delimitado período. A estratégia de busca na SCOPUS foi realizada no campo advanced utilizando os termos: "Stem* Cell*" AND "Brazil" AND ((PUBYEAR > 2012) AND (PUBYEAR < 2018)). Foram recuperados ao todo 10.569 documentos. Na base DII, foi utilizada a expressão de busca TS=("stem* cell*") AND PN=BR*, resultando em 1.375 patentes que foram depositadas no Brasil.

\section{RESULTADOS E DISCUSSÃO}

A produção científica nacional sobre células-tronco publicadas entre os períodos de 2013 a 2017 sofreu grande ascensão, chegando a 10.569 documentos. Desses documentos, $72,2 \%$ são artigos, $18 \%$ é artigo de revisão, 4,8\% são capítulos de livros, 1.2\% são livros, 1,0\% são trabalhos em eventos e 2,8 são os demais tipos de documentos (letter, preprint, editoriais). O gráfico 1 apresenta um crescimento contínuo na produção científica brasileira em célulastronco. Estudos como o de Santin, Nunez e Moura (2015), já apontavam a taxa de crescimento da pesquisa nessa temática. Levando em consideração que as autoras realizaram suas coletas na base de dados Web of Science, num período de quatorze anos, é notável que o interesse do Brasil e os investimentos feitos em pesquisas com células-tronco também vem crescendo positivamente. Desde que foi promulgada a Lei de Biossegurança e um investimento feitos pelo Ministério da Saúde em parceria com o CNPq, muitos grupos de pesquisa foram criados e se fortaleceram. Por meio desses investimentos, surgiu a Rede Nacional de Terapia Celular (RNTC), formada por oito Centros de Tecnologia Celular localizados em cinco estados brasileiros e por 52 laboratórios selecionados pelo $\mathrm{CNPq}$ (Conselho Nacional de Desenvolvimento Científico e Tecnológico) e pelo Departamento de Ciência e Tecnologia 
(Decit) do Ministério da Saúde. Sua principal função é ser mediadora entre pesquisadores de todo o Brasil e facilitadora de informações de pesquisas em células-tronco, acentuando o crescimento nacional em pesquisa com essa temática.

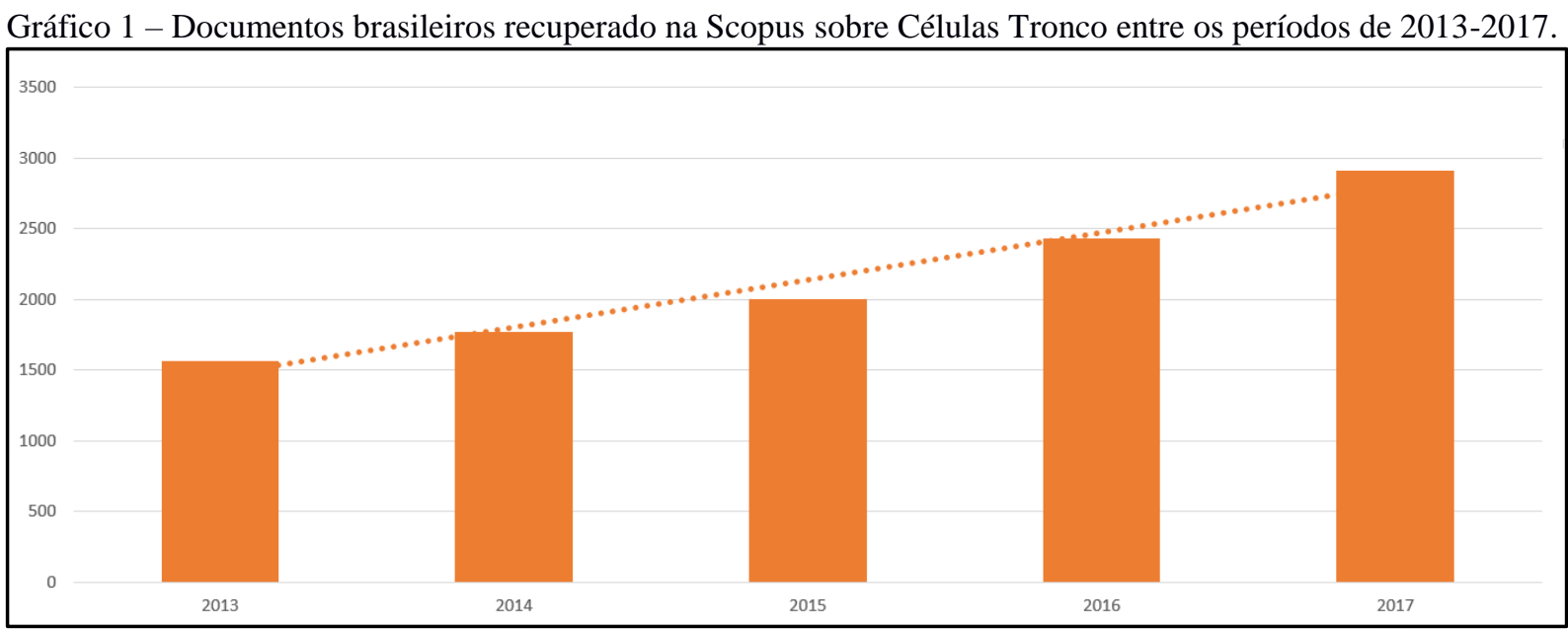

Fonte: Dados da Scopus, 2018.

Quanto às instituições, foram identificadas mais de 160 instituições que pesquisam células-tronco, porém, foram selecionadas as 10 instituições com maior produção científica nesse tema. Dos 10.589 documentos, 6.764 (64\%) correspondendo às instituições selecionadas conforme figura 1. São elas: Universidade de São Paulo (USP) que no período de cinco anos tem mais de 2261 documentos publicados, a Universidade Federal do Rio de Janeiro (UFRJ) com 744 documentos publicados, a Universidade Federal do São Paulo (UFSP) com 715 documentos, a Universidade Estadual Paulista (UNESP) com 677 documentos, a Universidade Estadual de Campinas (Unicamp)com 627 documentos, a Universidade Federal de Minas Gerais (UFMG) com 538 documentos, a Universidade Federal do Rio Grande do Sul (UFRGS) com 484 documentos, Fundação Oswaldo Cruz com 284 documentos, Universidade Federal do Paraná (UFP) 224 e a Universidade Federal de Santa Catarina (UFSC) com 210 documentos.

É perceptível que o cerne da pesquisa se encontra na região sudeste do Brasil, com maior concentração no Estado de São Paulo, onde apenas USP detém aproximadamente $20 \%$ do total de publicações recuperadas nesse período. Resultado que vai ao encontro da pesquisa das autoras Santin, Nunez e Moura (2015). As autoras selecionaram 15 instituições com maior número de publicações, num período de 14 anos. Dessas, sete foram encontradas nessa pesquisa. Demonstrando que, embora transcorrido quatro anos daquela pesquisa, a concentração de investimento em pesquisa com células-tronco permanece concentrada nas regiões sul e principalmente região sudeste. 
Figura 1 - Agrupamento (clustter) de instituições que mais publicaram pesquisa em células-tronco no Brasil e suas relações de colaboração entre 2013 e 2017.

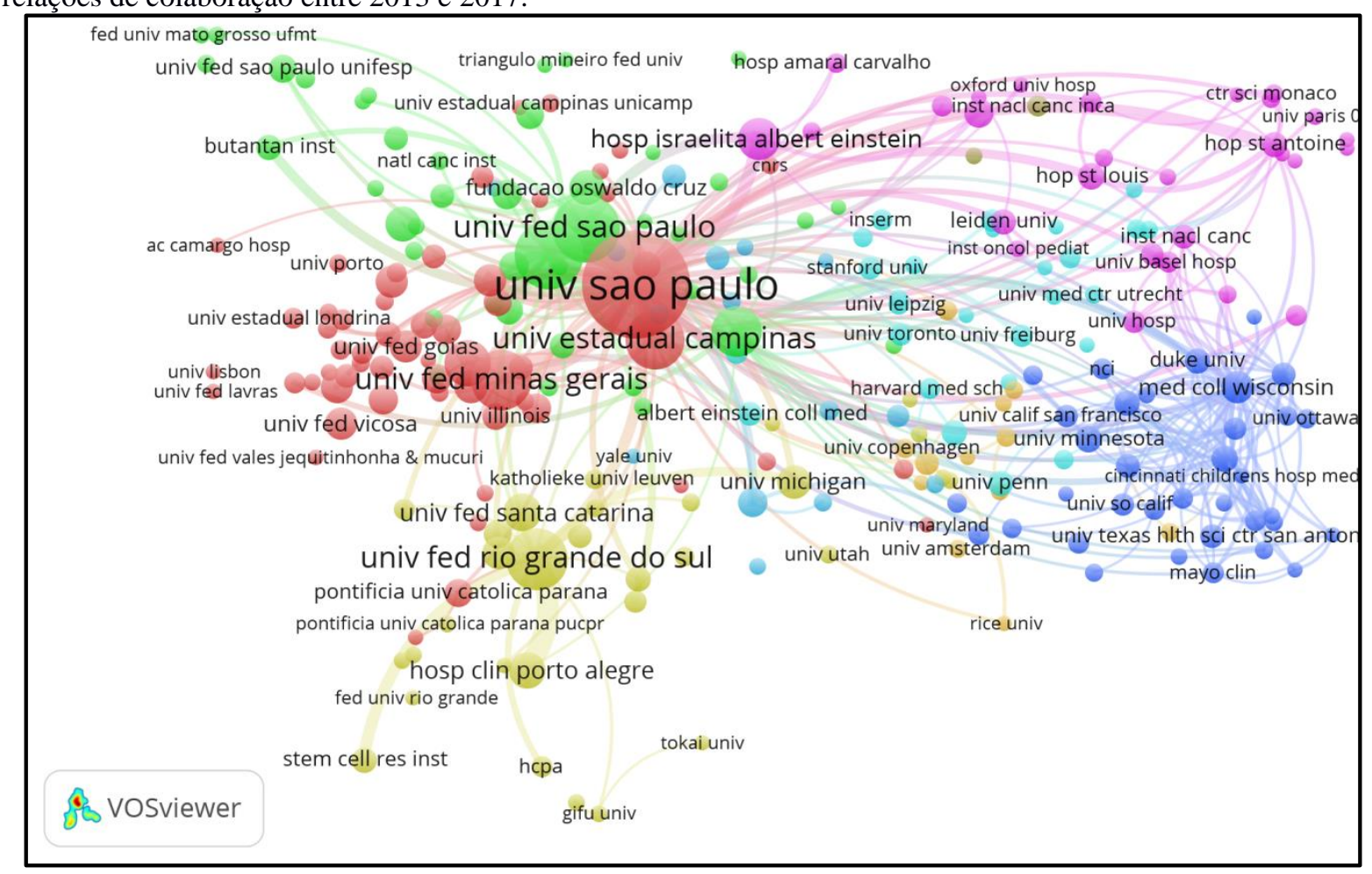

Fonte: dados da pesquisa, 2018.

Ainda na Figura 1 é possível observar uma forte colaboração entre as principais instituições selecionadas, bem como uma colaboração dessas com outras instituições mais periféricas. A UFRGS tem colaboração com Stem Cell Research Institute, assim como colaboração com o Hospital de Clínicas de Porto Alegre, que está sediado na própria universidade, além de forte colaboração com a Universidade Federal de Rio Grande (FURG), e Universidade Federal de Santa Catarina (UFSC). Provavelmente, isso se deve a proximidade geográfica dessas universidades.

Conforme estudos realizados por Leta (2002), há forte colaboração entre pesquisadores de outros estados e também com pesquisadores internacionais na área, o que aumenta o impacto das publicações brasileiras e a visibilidade das pesquisas. É possível observar na figura 2, analisando a proximidade dos clusters e os vértices que se ligam um país no outro, que o Brasil tem forte colaboração com os Estados Unidos da América, Reino Unido, Alemanha, Portugal e países da América do Sul, como Argentina, Chile e Uruguai. Essas colaborações já haviam sido observadas no estudo de Santin, Nunez e Moura (2015), onde as autoras, bem como Leta (2002), apontam que os EUA é o principal parceiro do Brasil em pesquisa com células-tronco. Isso certamente se deve ao fato dos EUA ser pioneiro nos estudos com células-tronco em 
camundongos, conforme afirma Machado (2015). Observa-se que existe uma interação entre Brasil e os países da América Latina, o que provavelmente está atrelado ao fato de proximidade geográfica entre esses países.

Figura 2 - Cluster de colaboração científica entre Brasil e outros países (2013-2017).

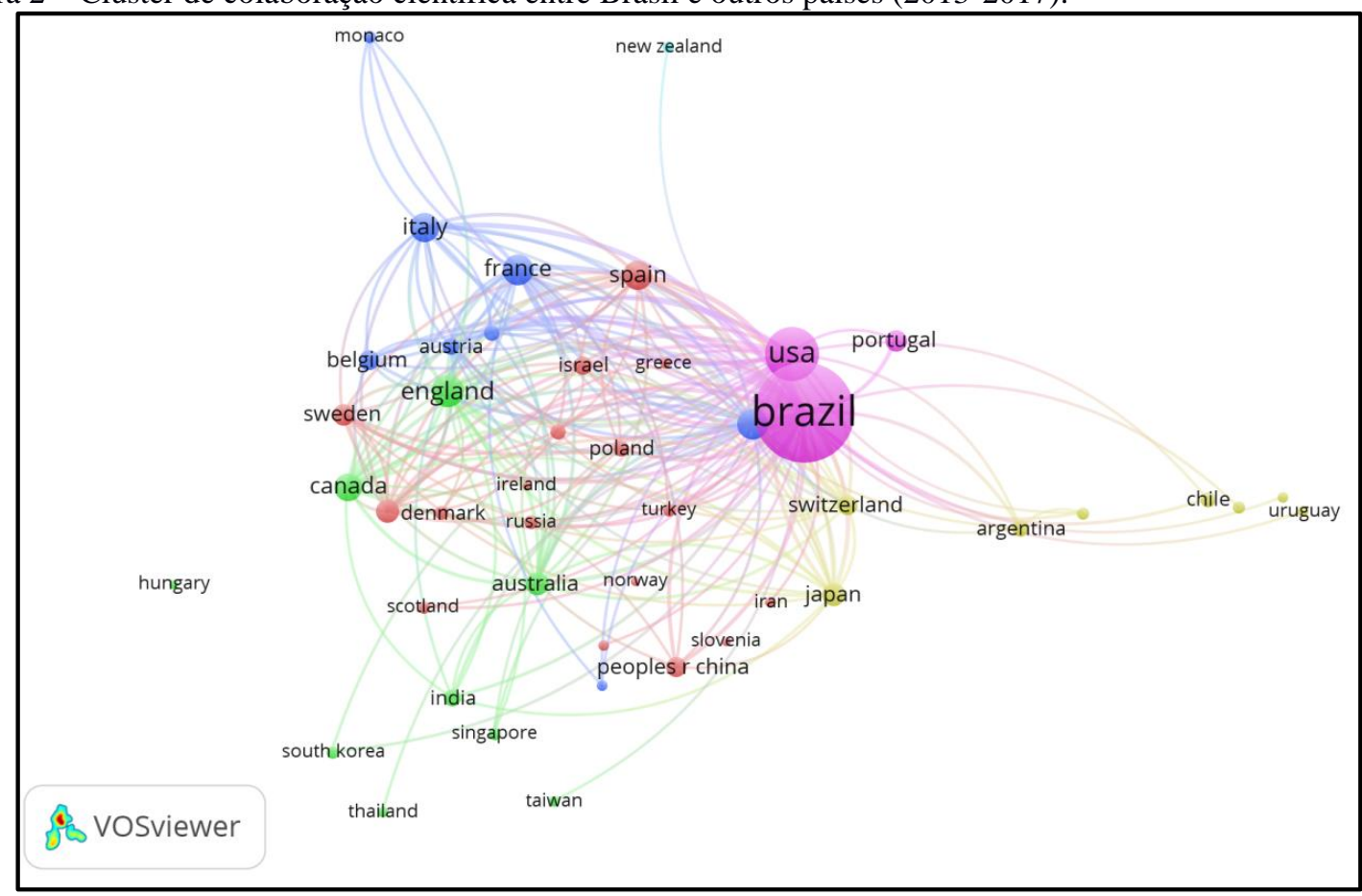

Fonte: dados da pesquisa, 2018.

A colaboração internacional tem sido eficaz no que tange a visibilidade e a valorização das pesquisas brasileiras, o que de acordo com Santin, Nunez e Moura (2015), pode influenciar positivamente o impacto das publicações, além de possibilitar novas colaborações internacionais.

Em relação aos escritórios de patentes, verifica-se que 1.089 das 1.375 patentes depositadas no Brasil foram depositadas via PCT pelo escritório internacional (WO), com 79,2\%. Seguindo do escritório norte-americano, com 201 patentes (14,6\%). Estes dois escritórios correspondem a 93,8\% de todas as patentes depositadas sobre células-tronco no Brasil. Não foi localizada nenhuma patente prioritária no Brasil, ou seja, patentes que fizeram o primeiro registro no Brasil. Não foi possível identificar neste estudo, patentes brasileiras que podem ter sido depositadas diretamente em escritórios internacionais, sem registrar prioritariamente no Brasil. E do total das 1.375 patentes recuperadas, apenas 14 não foram depositadas no escritório internacional (WO).

Na produção sobre o tema do estudo, o autor e pesquisador que possui maior número de publicações é o médico Nelson Hamerschlak, formado pela USP, tem experiência em doenças 
com: anemias, agranulocitose, hemostasia e trombose, leucemias, linfomas, mieloma múltiplo, transplantes de medula óssea, doenças autoimunes e hemoterapia. Profissional vinculado as seguintes instituições: Hospital Israelita Albert Einstein, Sociedade Brasileira de Hematologia e Hemoterapia (SBHH) Associação Brasileira de Hematologia, Hemoterapia e Terapia Celular, (ABHHHTC).

Outro pesquisador que se encontra no centro das pesquisas com células-tronco é o médico, Dimas Tadeu Covas. Graduado em Medicina pela Universidade de São Paulo, mestrado em Medicina pela Universidade de São Paulo, doutorado em Medicina pela Universidade de São Paulo, diretor do Instituto Butantan, diretor-Presidente da Fundação Hemocentro de Ribeirão Preto que é responsável pelo atendimento transfusional em uma área geográfica com 4 milhões de habitantes; coordenador do Centro de Terapia Celular (CTCCEPID-FAPESP) e coordenador do Instituto Nacional e Ciência e Tecnologia em CélulasTronco e Terapia Celular (INCTC). Membro Titular do Conselho Consultivo do Comitê Estratégico para assuntos de transplantes e doação de órgãos do Ministério da Saúde, Membro Titular da Câmara Técnica da Coordenação de Sangue e Hemoderivados do Ministério da Saúde. É hematologista e hemoterapêuta e desenvolve pesquisas nos seguintes temas: biologia molecular e celular, células-tronco, antígenos eritrocitários e plaquetários, vírus (HIV e HTLV), expressão heteróloga de proteínas em sistemas celulares in vitro. Foi membro titular da CTNBio de 2008 a 2011. É editor associado da Revista Brasileira de Hematologia e Hemoterapia e Editor Acadêmico da revista PLOsOne. Ganhou o Prêmio Jabuti da Câmara Brasileira do Livro em 2007 com o livro: Células-Tronco - A nova fronteira da medicina. Membro pesquisador da Rede Nacional de Terapia Celular (RNTC) e Associação Brasileira de Hematologia, Hemoterapia e Terapia Celular (ABHH).

Alexander Henning Ulrich, possui graduação em Biologia pela Universitat Kiel (Christian-Albrechts), mestrado em Parasitologia - Universitat Kiel (Christian-Albrechts), doutorado em Neurociências pela Universidade de Hamburgo (Center for Molecular Neurobiology. Fez pós-doutorado na Universidade de Hamburgo (Center for Molecular Neurobiology), Universidade Cornell e no Instituto de Química, USP. É Professor Titular do Dep. de Bioquímica, Instituto de Química, Universidade de São Paulo, editor Acadêmico do periódico PLos ONE, editor Associado dos periódicos Cytometry Part A, Purinergic Signalling, Stem Cell Reviews \& Reports, Journal of Cancer Stem Cell Research. Linhas de pesquisa: aptâmeros de RNA e DNA como ligantes específicos de células tronco e tumorais; farmacologia de receptores purinérgicos e de cininas; diferenciação neural, neurodegeneração e neurorregeneração e participação de sinalização de cálcio intracelular e receptora de 
metabotrópicos e ionotrópicos (purinérgicos, cininérgicos e colinérgicos) neste processo. Vinculado a Universidade de São Paulo, Escola Paulista de Medicina, UNIFESP, Centro de Toxinologia Aplicada (Instituto Butantan), CAT-CEPID é membro pesquisadora na Rede Nacional de Terapia Celular (RNTC).

Dos autores mais produtivos em artigos, destacam-se Alfredo Miranda de Goes possui graduação em pela Universidade Federal da Bahia, mestrado em pela Universidade Federal de Minas Gerais, doutorado pela Universidade Federal de São Paulo, pós-doutorado pela Texas A\&M University, Texas, USA. Atualmente é professor titular da Universidade Federal de Minas Gerais e pesquisador $1 \mathrm{~A}$ do $\mathrm{CNPq}$. Tem experiência na área de Bioquímica e Imunologia, com ênfase em Bioquímica e Imunologia dos Microorganismos, atuando principalmente nos seguintes temas: O Laboratório de Imunologia Celular e Molecular, inflamação granulomatosa, marcadores de diagnósticos, formulação de vacinas em doenças infecto-contagiosas, câncer de mama e regeneração óssea, de cartilagem e de neurônios usando células tronco mesenquimais ou embrionárias. Está vinculado a Universidade Federal de Minas Gerais, e é membro pesquisador da Rede Nacional de Terapia Celular (RNTC).

Patricia Helena Lucas Pranke é graduada em Farmácia pela Universidade Federal de Santa Maria, mestrado em Ciências Médicas pela Universidade Estadual de Campinas, doutorado em Genética e Biologia Molecular pela Universidade Federal do Rio Grande do Sul e doutorado sanduíche no laboratório de células-tronco do New York Blood Center, Estados Unidos, na área de células-tronco. Pós-doutorado na Phillip Marburg Univsersity, Alemanha na área de nanotecnologia e engenharia de tecidos/medicina regenerativa. Membro da diretoria da Sociedade Latino Americana de Biomateriais e Órgãos Artificiais. Membro do conselho da sociedade internacional: Tissue Engineering and Regenerative Medicine International SocietyAmericas. Membro dos grupos diretores internacionais - International Stem Cell Banking Initiative (ISCBI) e International Stem Cell Initiative (ISCI). Foi uma das duas cientistas brasileiras que prestou assessoria ao Senado e Congresso Federal na elaboração da lei de Biossegurança, que aprovou as pesquisas com células-tronco embrionárias humanas no Brasil. Pesquisadora da Associação Brasileira de Hematologia e Hemoterapia, membro pesquisador da International Society for Stem Cell Research. Atual presidente do conselho do Instituto de Pesquisa com Células-tronco. Fundadora e primeira presidente do Instituto de Pesquisa Com Célula-tronco. Professora no programa de Pós-graduação em Fisiologia, da Universidade Federal do Rio Grande do Sul. Tem experiência na área de células-tronco e nanotecnologia, atuando principalmente nos seguintes temas: células tronco adultas, sangue de cordão umbilical, células tronco embrionárias/pluripotentes, nanotecnologia, engenharia de tecidos e 
medicina regenerativa. Está vinculada a: Universidade Federal do Rio Grande do Sul (UFRGS), Instituto de Pesquisa Com Célula Tronco, IPCT, International Society for Stem Cell Research (ISSCR), Estados Unidos, Associação Brasileira de Hematologia e Hemoterapia (ABHH), International Stem Cell Banking Initiative, (ISCBI). Além de ser membro pesquisadora da Rede Nacional de Terapia Celular (RNTC).

Com base no currículo dos pesquisadores é possível notar que, exceto Nelson Hamerschlak, todos os demais são membros da Rede Nacional de Terapia Celular, o que reforça a proposta da RNTC em servir como mediadora entre pesquisadores interessados em estudos com células-tronco. Observa-se também que a maioria dos pesquisadores tem vínculo com a USP, o que evidencia a ideai de centralidade na pesquisa com células-tronco nessa região. É interessante observar a heterogeneidade das áreas dos pesquisadores que mais publicaram em células-tronco no período de 2013-2017. Além disso, nota-se que mesmo os pesquisadores nascidos em outros países são professores vinculados às universidades brasileiras, demonstrando o interesse nessa temática não somente de pesquisadores nascidos no Brasil, mas de outros países.

Ao analisar o currículo lattes desses pesquisadores, foi observado que alguns possuem patentes na área de células-tronco, o que poderá contribui positivamente para estudos futuros. Entretanto, como será visto mais adiante, o depósito não ocorreu prioritariamente no escritório brasileiro, mas prioritariamente em outros países. Nesse estudo não se pode chegar a uma conclusão desse fato, mas parte-se da hipótese que a área de células tronco está se desenvolvendo muito rapidamente, a opção de deposito internacional se dá pela agilidade na concessão da patente, que no Brasil em média demora 7 anos, contra 2 meses da Suíça e um ano nos Estados Unidos, mas essa afirmação precisa ser confirmada com os pesquisadores. 
Figura 3 - Frequência de artigos científicos pelas áreas do conhecimento da Scopus.

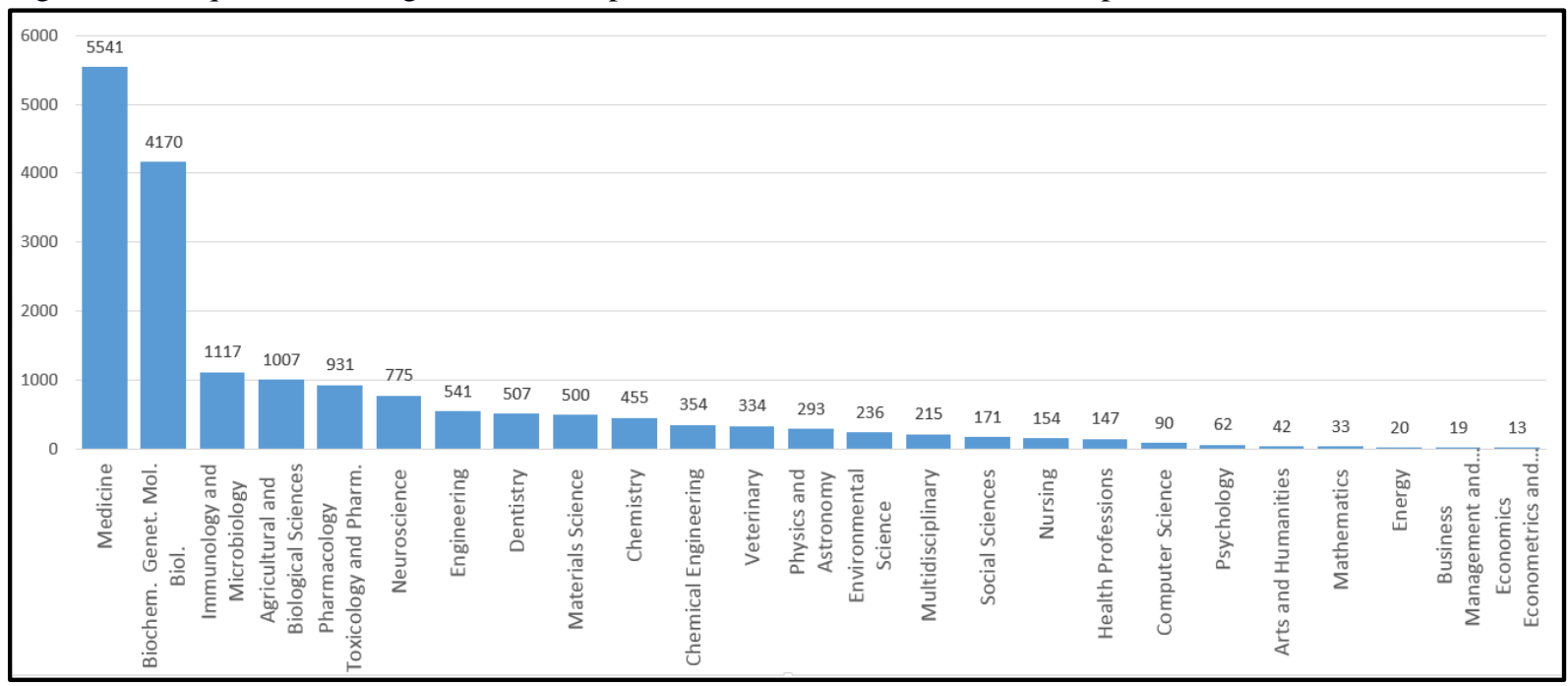

Fonte: dados da pesquisa, 2018.

Nas análises das relações entre os artigos (Figura 3) e das patentes (Figura) em Células Tronco, pode-se observar que as publicações científicas se concentram principalmente nas áreas de Medicina com 5.541 artigos (31,3\%) e Bioquímica, Genética Molecular com 4.170 (23,5\%), sendo predominantes na pesquisa científica. Enquanto nas patentes a distribuição das classificações dos assuntos não tem tanta disparidade, apresentando uma melhor distribuição. A maior concentração de temática dentro das patentes, destacam-se os Fármacos com 486 patentes $(7,1 \%)$, Preparações médicas e odontológicas e Agentes antineoplásicos (tratamento do câncer) ambos com 447 (6,5\%), e Tecnologia do DNA recombinante com 379 patentes $(5,5 \%)$.

Podemos considerar que o Brasil produz conhecimento em Células Troco, visto o grande número de publicações realizada por pesquisadores, entretanto ainda existe a dependência tecnologia de outros países. A grande produção brasileira refere-se está relaciona as áreas médicas e de saúde, porém, para realizar as pesquisas existe a dependência de medicamentos, preparações, agentes antineoplásticos e enzimas, materiais, anticorpos entre outros de países como os Estados Unidos e da Europa.

Ao analisar os maiores depositantes de patentes observa-se que a concentração se faz pelos grandes laboratórios de medicamentos, como a Janssen Biotech com 56 patentes $(4,07 \%)$, empresa essa de biotecnologia fundada na Filadélfia em 1979, do ramo farmacêutico, incialmente tinha o objetivo de desenvolver novos testes diagnósticos usando a tecnologia de anticorpos monocionais, posteriormente ampliou seus negócios para a Leiden na Holanda, em 1999 tornou-se subsidiária da Johnson \& Johnson. 
Outra grande empresa detentora de registros de patentes no Brasil é a Hoffman La Roche com 30 patentes $(2,18 \%)$ e pelo Holding Hoffman La Roche com outras 24 patentes $(1,7 \%)$. Empresa também do ramo farmacêutico, fundada em 1896 com base na Suíça, hoje é categorizada como uma empresa multinacional que opera em todo o mundo sob duas divisões, a farmacêutica e a diagnóstica. A Empresa controla diversas outras empresas de biotecnologia, sendo a terceira maior empresa farmacêutica do mundo.

A GlaxoSmithKline com 29 patentes $(2,11 \%)$, também do ramo farmacêutico, é uma empresa britânica sediada em Brentford, Londres, fundada em 2000 com a fusão da Glaxo Wellcome e da SmithKline Beecham, a GSK como é conhecida, é a sexta maior empresa do ramo farmacêutico. Pesquisa e desenvolve produtos principalmente em medicamentos e vacinas, mas incluem uma diversificação de produtos.

Figura 4 - Frequência das patentes depositadas no Brasil sobre Células Tronco (Stem Cell).

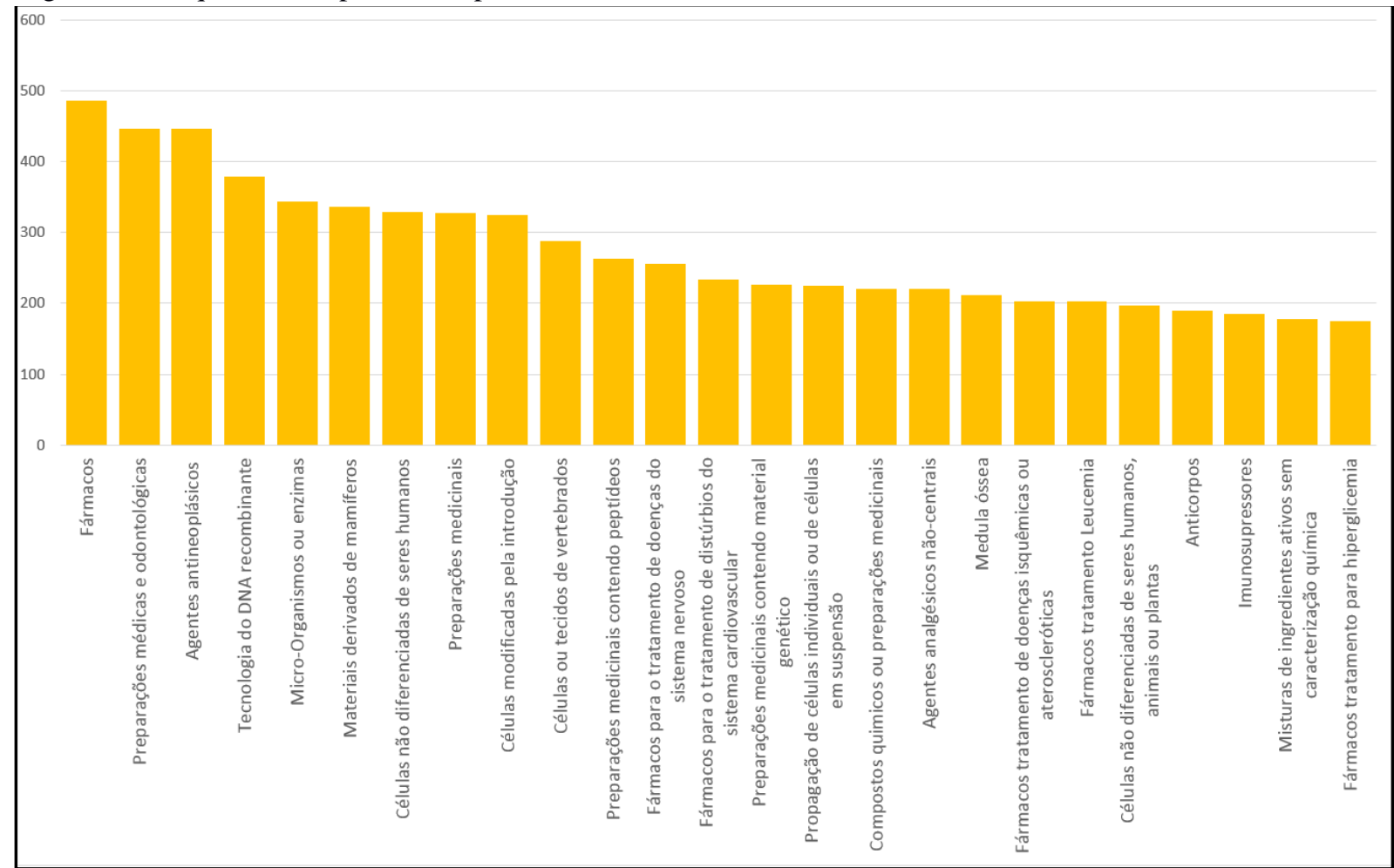

Fonte: dados da pesquisa, 2018.

A Novartis com 25 patentes $(1,8 \%)$, novamente do ramo farmacêutico, tem sua sede na Suíça, sendo considerada uma das maiores empresas de fármacos do mundo se considerar as vendas. A Novartis fabrica as drogas clozapina (Clozaril), diclofenaco (Voltaren), carbamazepina (Tegretol), valsartana (Diovan), mesilato de imatinibe (Gleevec / Glivec), ciclosporina (Neoral / Sandimmun), letrozol (Femara), metilfenidato (Ritalina), terbinafina (Lamisil) e outros. 
Dentre as cinquenta empresas que mais depositaram patente em território brasileiro, não foi identificado nenhuma do Brasil. Pode-se observar a hegemonia das grandes empresas multinacionais, e nenhuma relação, entre as maiores depositantes, com os pesquisadores brasileiros.

\section{CONSIDERAÇÕES FINAIS}

Os resultados obtidos nesse estudo revelam que há um crescimento positivo na produção científica brasileira em células-tronco. Fatores como o investimento do Ministério da Saúde (MS), Ministério Ciência e Tecnologia (MCT), o Conselho Nacional de Desenvolvimento Científico e Tecnológico (CNPq) e a Financiadora de Estudos e Projetos (FINEP) muitos editais para criação de grupos de pesquisa em células-tronco foram abertos. Como eles vieram as Associações como: Associação Brasileira de Hematologia, Hemoterapia e Terapia Celular, (ABHHHTC), Associação Brasileira de Hematologia e Hemoterapia (ABHH), International Stem Cell Banking Initiative, (ISCBI), os Centros de Tecnologia Celular, vinculados a Rede Nacional de Terapia Celular (RNTC), além das instituições internacionais que vem colaboração com as pesquisas brasileiras.

As produções científicas sobre células-tronco, como observado em estudos nas mais variam áreas e temáticas, concentram-se nas regiões sul e sudeste, com grande ocorrência em instituições públicas. Entre as instituições mais produtivas, destacam-se a USP, UFRJ, UFSP, UNESP, Unicamp, UFMG, UFRGS, Fundação Oswaldo, UFP e UFSC. Além disso, a produção científica brasileira em células-tronco apresenta uma forte interação com instituições internacionais, apresentando forte colaboração com países como EUA, Japão, Itália, França, Reino Unido, Argentina, Chile e Uruguai.

Contudo, toda essa pesquisa não se reflete na área tecnológica com o registro de patentes, principalmente registradas no Brasil. Observou-se pelo currículo de alguns pesquisadores, que estes têm patentes registradas, mas nesse estudo não foi possível identificalas, sendo necessário uma análise qualitativa de onde e como ocorreram esses depósitos, e quem é o detentor dos direitos de licenciamento. Não foi localizado nenhuma patente registrada prioritariamente no Brasil, sendo o pais dependente de tecnologias dos outros países na área de células tronco, principalmente no fornecimento de fármacos.

Pode-se considera que o Brasil está se tornando um importante agente produtor de pesquisa em células-tronco, tanto no número de publicações, como no número de instituições nacionais voltadas para esse fim, bem como na colaboração entre pesquisadores nacionais e 
internacionais. O que proporciona visibilidade aos pesquisadores e ao país e possibilidades de maiores investimentos e internacionalização.

Conclui-se, então, que os resultados não apresentam uma correspondência direta na produção de ciência e a produção de tecnologias na área de células tronco no Brasil, e que o país é dependente de tecnologia de outros países. Espera-se que o crescimento da produção científica brasileira possa contribuir para o desenvolvimento tecnológico, e o registro de patentes no Brasil. 


\section{REFERENCIAS}

ARAGÃO, M. A. C.; BEZERRA, F. T. G. Brasil e as pesquisas com células-tronco: visão geral. Revista da Biologia, v. 9, n. 1, p. 12-15, 2012.

BARFOOT, J. et al. Stem cell research: trends and perspectives on the evolving international landscape. Amsterdam: Elsevier, 2013. Disponível em:< https://www.elsevier.com/_data/assets/pdf_file/0005/53177/Stem-Cell-Report-Trends-andPerspectives-on-the-Evolving-International-Landscape_Dec2013.pdf>. Acesso em: 18 fev. 2018.

BRASIL. Lei 8.974 de janeiro de 1995. Regulamenta os incisos II e V do $§ 1^{\circ}$ do art. 225 da Constituição Federal, estabelece normas para o uso das técnicas de engenharia genética e liberação no meio ambiente de organismos geneticamente modificados, autoriza o Poder Executivo a criar, no âmbito da Presidência da República, a Comissão Técnica Nacional de Biossegurança, e dá outras providências. Diário Oficial [da] República Federativa do Brasil, Brasília, DF, 6 jan. 1995. Disponível em: <http://www.planalto.gov.br/ccivil_03/leis/L8974.htm>. Acesso em: 18 fev. 2018.

BRASIL. Lei 11.105 de março de 2005. Regulamenta os incisos II, IV e V do § 1o do art. 225 da Constituição Federal, estabelece normas de segurança e mecanismos de fiscalização de atividades que envolvam organismos geneticamente modificados - OGM e seus derivados, cria o Conselho Nacional de Biossegurança - CNBS, reestrutura a Comissão Técnica Nacional de Biossegurança - CTNBio, dispõe sobre a Política Nacional de Biossegurança PNB, revoga a Lei no 8.974, de 5 de janeiro de 1995, e a Medida Provisória no 2.191-9, de 23 de agosto de 2001, e os arts. 5o, 6o, 7o, 8o, 9o, 10 e 16 da Lei no 10.814, de 15 de dezembro de 2003, e dá outras providências. Diário Oficial [da] República Federativa do Brasil, Brasília, DF, 28 mar. 2005. Disponível em:<http://www.planalto.gov.br/ccivil_03/_ato20042006/2005/lei/111105.htm>. Acesso em: 18 fev. 2018.

BRISOLLA, S. et al. As relações universidade-empresa-governo: um estudo sobre a Universidade Estadual de Campinas (UNICAMP). Educ. Soc.[online], v. 18, n. 61, p.187209, 1997.

DINIZ, D.; AVELINO, D. Cenário Internacional da pesquisa em células-tronco embrionárias. Revista Saúde Pública, v. 43, n. 3, p. 541-547, 2009. Disponível em: < http://www.scielo.br/pdf/rsp/v43n3/414.pdf>. Acesso em: 15 mar. 2018.

LETA, J.; CHAIMOVICH, H. Recognition and international collaboration: the Brazilian case. Scientometrics, v. 53, n. 3, p. 325-335, mar. 2002. Disponível em: $<$ https://link-springercom.ez45.periodicos.capes.gov.br/article/10.1023/A\%3A1014868928349 >. Acesso em: 6 mar. 2018.

MACHADO, R. N. Estrutura intelectual da literatura científica do Brasil e outros países dos BRICS: uma análise de cocitação de periódicos na área de célula-tronco. 2015. 366 f. Tese (Doutorado) - Programa de Pós-graduação em Ciência da Informação do Instituto Brasileiro de Informação em Ciência e Tecnologia, Universidade Federal do Rio de Janeiro, Rio de Janeiro, 2015. 
NARDI, N. B. Células-tronco: fatos, ficção e futuro. Genética na escola, v. 2, n. 2, p. 25-29, jul./dez. 2017. Disponível em: 〈http://www.cellvet.com.br/2.pdf〉. Acesso em: 15 mar. 2018.

RODRIGUES, P. C. R. Células-tronco e terapia regenerativa do tecido muscular cardíaco. 2006. 58f. Monografia (Trabalho de Conclusão de Curso)- Escola Politécnica de Saúde Joaquim Venâncio, Rio de Janeiro, 2006. Disponível em:

<http://www.hlog.epsjv.fiocruz.br/upload/monografia/44.pdf>. Acesso em: 01 mar. 2018.

SANTIN, D. M.; NUNEZ, Z. A. G.; MOURA, A. M. M. Produção científica brasileira em células-tronco nos anos 2000 a 2013: características e colaboração internacional. Revista Eletrônica de Comunicação, Informação \& Inovação em Saúde, v. 9, n. 2, p. 1-16, abr;/jun. 2015. Disponível em:<https://www.arca.fiocruz.br/bitstream/icict/17035/2/5.pdf>. Acesso em: 27 fev. 2018.

THOMSON, J. A. et al. Embryonic stem cell lines derived from human blastocysts. Science, v. 282, p. 1145-1147, nov. 1998. Disponível em:

<http://science.sciencemag.org/content/282/5391/1145/tab-pdf>. Acesso em: 01 mar. 2018. 